\title{
Reassessment of the La Ferrassie 3 Neandertal ossicular chain
}

\author{
Rolf Quam $^{\text {a,b,c,*, Ignacio Martínez }}{ }^{\text {b,d }}$, Juan Luis Arsuaga ${ }^{\text {b,e }}$ \\ ${ }^{a}$ Department of Anthropology, Binghamton University (SUNY), Binghamton, NY 13902-6000, USA

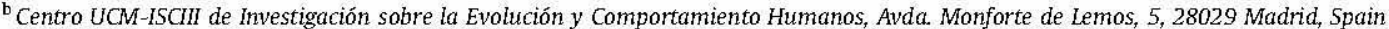 \\ ${ }^{\complement}$ Division of Anthropology, American Museum of Natural History, Central Park West at 79th Street, New York, NY 10024-5192, USA \\ ${ }^{\mathrm{d}}$ Universidad de Alcalá, Departamento de Geología (Área de Paleontología), Edificio de Ciencias, Campus Universitario, 28871 Alcalá de Henares, Spain \\ ${ }^{\circledR}$ Universidad Complutense de Madrid, Departamento de Paleontología, Facultad de Ciencias Geológicas, Ciudad Universitaria s/n, 28040 Madrid, Spain
}

\section{Keywords:}

Malleus

Incus

Stapes

Middle ear

Evolution

Homo neanderthalensis

\begin{abstract}
A B S T R A C T
The ossicular chain in La Ferrassie 3 was briefly described in the monograph on the La Ferrassie Neandertal children, but to date has not been the subject of detailed study. We provide new data on these important fossils and re-examine some previous suggestions of derived Neandertal features in the middle ear ossicles based on more limited evidence. The malleus shows a curved lateral margin of the manubrium and a relatively large head. The incus shows a tall articular facet, a depressed area on the medial surface of the body, a straight anterior border of the long process and a more closed angle between the processes. The stapes shows an asymmetrical configuration of the crura, with an anteriorly skewed head, and generally small dimensions, including a smaller and relatively wider stapedial footplate. These same features can also be seen in the few other Neandertal ear ossicles known, suggesting that a consistent anatomical pattern characterizes the Neandertal ossicular chain. While the phylogenetic polarity of many of these features remains to be clarified, the asymmetrical stapes and anteriorly skewed stapedial head appear to be derived Neandertal features. In addition, while the larger malleus head and incus articular facet in La Ferrassie 3 might reflect larger body mass in Neandertals, the larger stapes footplates in Homo sapiens cannot be explained by changes in body mass. Indeed, $\mathrm{H}$. sapiens seems to depart from the general mammalian pattern in combining an increase in stapes footplate size with a decrease in body mass. Although the malleus/incus lever ratio in La Ferrassie 3 is similar to that in $H$. sapiens, Neandertals appear to be characterized by a slightly different spatial relationship and articulation of the ossicular chain within the tympanic cavity. While only limited inferences can be drawn regarding hearing ability based on the ossicles, the few physiologically relevant dimensions in the La Ferrassie 3 ear bones are similar to $H$. sapiens.
\end{abstract}

\section{Introduction}

The La Ferrassie 3 (LF3) Neandertal is one of the very few human fossil specimens to preserve a complete ossicular chain (malleus, incus and stapes). The bones were briefly described and a few metric dimensions were provided by Heim in the monograph on the La Ferrassie Neandertal children (Heim, 1982). ${ }^{1}$ Heim suggested that the Neandertal ossicles were distinct from those of fossil and

\footnotetext{
* Corresponding author.

E-mail address: rquam@binghamton.edu (R. Quam).

1 Heim (1982) also mentions the presence of an incus within the tympanic cavity in La Ferrassie 4 bis. This specimen was said to closely resemble the incus in the LF3 individual. However, examination of the original specimen did not reveal the presence of an incus, nor is a photo of the specimen included in the monograph on the La Ferrassie children. Thus, the existence of this specimen is currently known only from the reference to it by Heim.
}

recent Homo sapiens in a number of subtle aspects. In particular, the malleus in LF3 was slightly longer, with a larger head and a more open angle between the manubrium and the head/neck. In addition, the manubrium was relatively straight with a well-developed lateral (short) process, the latter implying a greater protrusion of the tympanic membrane. The incus shows a longer long process, which is relatively straight and thin. In contrast, the short process is shorter and does not show a notch in its lower border. The articular surface is described as large and the body as slightly flatter than in $H$. sapiens. The stapes is slightly smaller and shows a pronounced asymmetry between the shorter anterior crus and the longer and more curved posterior crus. The head of the stapes is skewed anteriorly and the crura are thicker in LF3. In sum, the Neandertal ear ossicles are said to differ from $H$. sapiens in the larger dimensions of the malleus and incus, the smaller size and asymmetry of the stapes, the more open angle of the malleus and a more closed 
angle of the incus (Heim, 1982). Nevertheless, Heim was appropriately cautious in interpreting whether these slight differences held any evolutionary significance or were merely the result of individual variation.

Several more recent studies have provided additional data for the LF3 ossicles (Masali et al., 1991; Spoor, 2002; Crevecoeur, 2007; Quam and Rak, 2008), based largely on measurements obtained from the scaled photo published by Heim. Since the original specimens were previously unavailable for study, this represented the only approach possible to obtain further metric data on these specimens. However, given the quality of the photograph, the imprecise orientation and very small size of the ossicles, this data should be considered tentative. On a recent trip, one of us (RMQ) was able to study the original fossil specimens.

Several developments since the original publication make a reassessment of the LF3 ear ossicles warranted. Studies of the inner ear in Neandertals have revealed differences from $H$. sapiens in several aspects (Spoor et al., 2003), and despite their diminutive size, the middle ear ossicles are particularly well-suited to drawing phylogenetic inferences. At birth, these tiny bones are fully formed and have already reached adult dimensions (Scheuer and Black, 2000). The embryological origin of each of the ear bones has been thoroughly studied, and their development is under tight genetic control (Mallo, 1998, 2001; Frenz et al., 2001). Comparative genomic studies have revealed accelerated rates of evolution in several genes related to hearing in humans compared with chimpanzees (Clark et al., 2003), including some (e.g., Eya1) that may be directly related to the formation of the ossicles (Xu et al., 1999). A standardized measurement protocol, relying in part on previous studies (Masali, 1964), has been developed for the auditory ossicles (Quam and Rak, 2008), and the fossil sample of these tiny bones has been augmented considerably (Arensburg et al., 1996; Tillier, 1999; Maureille, 2002; Spoor, 2002; Lisonek and Trinkaus, 2006; Quam et al., 2006; Crevecoeur, 2007). In addition, the ear ossicles play an important physiological role in audition (Wever and Lawrence, 1954; Kirikae, 1960). Anatomical differences in the ear ossicles across primates have been shown to be correlated with aspects of their hearing sensitivity (Coleman and Ross, 2004; Coleman and Colbert, 2010), and fossil hominin ear ossicles have been included in models that reconstruct the auditory capacities in hominin species (Martínez et al., 2004, in press; Quam et al., 2012).

The preservation of a complete ossicular chain in LF3 is exceptional. The only other published fossil hominin specimens to preserve all three ear ossicles are the Middle Paleolithic $H$. sapiens specimen from Darra-i-Kur (Angel, 1972) and the recently rediscovered Le Moustier 2 Neandertal infant (Maureille, 2002). In addition to LF3, published data on Neandertal ear ossicles is mainly limited to the stapes from Subalyuk 2 and the incudi from Amud 7 and Le Moustier 1 (Arensburg et al., 1996; Ponce de León and Zollikofer, 1999; Quam and Rak, 2008). The study of the ear ossicles in LF3, then, provides an opportunity to confirm the limited observations made on these isolated specimens and promises to reveal new insights into the evolution of the auditory apparatus in Neandertals.

\section{Materials and methods}

\section{The La Ferrassie 3 ear ossicles}

The three ear ossicles were recovered from the right tympanic cavity. Since the original publication, the LF3 ear ossicles have suffered some damage, which limits the information that can be obtained. The malleus appears to be complete, but is broken in two pieces, corresponding to the manubrium and the head/neck (Fig. 1). These have been glued together in the past, although they are

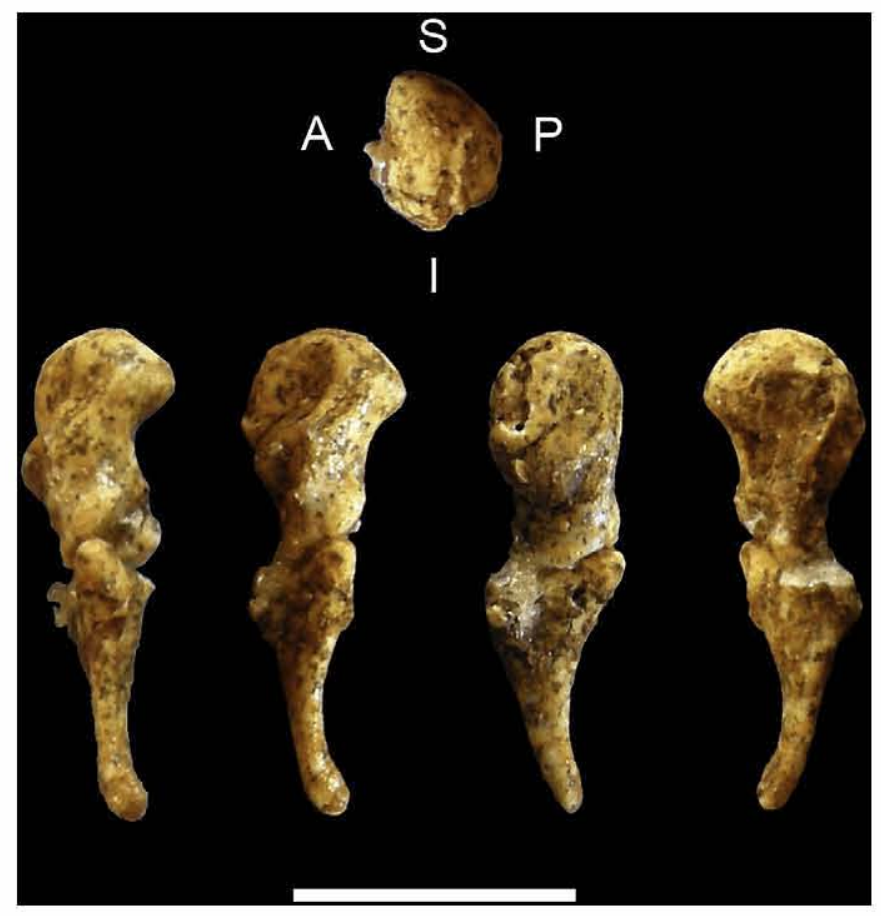

Figure 1. The LF3 malleus. The bone appears to be complete, but the two major fragments are incorrectly aligned, prohibiting a standard view of the bone. The view on the far left corresponds approximately to the view published by Heim (1982). The other three views show slightly different orientations of the bone. Note the curvature of the lateral surface of the manubrium. Scale bar $=5 \mathrm{~mm}$.

currently not in their proper anatomical position. In particular, the head/neck is glued to the superior border of the lateral process, rather than joining with the manubrium laterally. This has the effect of artificially elongating the specimen and the typical angulation between the head and the manubrium is not accurately represented. Close comparison of the present-day specimen with the photograph published by Heim (1982) indicates that the specimen was already in its present state at the time of its publication. This means that the metric dimensions published previously by Heim and others need to be revised. Examination under a standard light microscope reveals that both the tip of the manubrium and the lateral process are complete and undamaged. However, the top of the head shows some erosion of the surface bone near the margin of the articular facet. The incorrect orientation of the two main pieces and the thick coating of adhesive prevent observation of a few anatomical features.

Although the true maximum length cannot currently be determined, the maximum length of the bone as it is presently (incorrectly) reconstructed was measured in several slightly different orientations of the bone (Fig. 1), including the view that appears to correspond to that published by Heim. The highest value obtained in any of these views was $8.74 \mathrm{~mm}$ (8.54-8.74 $\mathrm{mm}$ range). This value is larger than that reported by Heim $(8.3 \mathrm{~mm})$, but shorter than that measured by Spoor $(2002)(9.0 \mathrm{~mm})$ and Crevecoeur (2007) $(8.9 \mathrm{~mm})$ on the published photograph. Although all of these estimates are unreliable since they were taken on the incorrectly reconstructed malleus, the true maximum length is unlikely to be as long as $9.0 \mathrm{~mm}$, as suggested by Spoor (2002).

Given the preservation conditions, every attempt was made to measure as many standard dimensions as possible, paying close attention to preservation of the bone and identification of reliable anatomical landmarks. Despite these preservation issues, measurements of the manubrium and head/neck in the present study 
should be considered reliable. However, the angulation between the manubrium and head/neck as well as the corpus length and the total length of the bone cannot be accurately assessed.

The published photograph of the stapes reveals that this bone was complete and intact at the time of publication (Heim, 1982). Currently, the bone is nearly complete, but broken in four pieces and covered with adhesive (Fig. 2). Given their extremely fragile state, no attempt was made to separate the pieces to reconstruct the bone more accurately. The largest piece corresponds to the intact head and includes approximately the superior one-third of the anterior crus. A second piece comprises the superior two-thirds of the posterior crus. A third piece corresponds to the inferior twothirds of the anterior crus and a portion of the footplate. The fourth piece corresponds to the inferior one-third of the posterior crus and a portion of the footplate. The footplate itself appears to be missing a portion of the bone in the middle section. The four pieces were glued together in their approximate relative positions, but do not articulate directly with one another, making the correct anatomy difficult to discern.

The only reliable measurement that can be taken on this bone in its current state of preservation is the head height. Heim (1982) provides values for the total height of the stapes and the footplate length, measured when the bone was complete. In addition, Masali et al. (1991) provide the lengths of the anterior and posterior crura, as well as the area of the stapes footplate.

We have relied on two sources to evaluate the accuracy of the stapes height and the lengths of the anterior and posterior crura. We have measured the total stapes height and the lengths of the crura in the published scaled photograph of the original specimen, finding a close correspondence with the values reported by Heim (1982) and Masali et al. (1991). In addition, we have estimated the total stapes height and the anterior crus length in the scaled photograph taken for the present study, even though the bone is damaged. Again, a fairly close correspondence with the published values is found, suggesting that these measurements are accurate. The posterior crus length could not be evaluated in the present state of preservation of the stapes, but given good correspondence with the total height and the anterior crus length, we have accepted this value to be accurate as well.

The footplate length and area cannot currently be measured in the LF3 stapes since the footplate is damaged. However, the footplate dimensions can be reliably estimated from the oval window visible on the medial wall of the tympanic cavity. The footplate

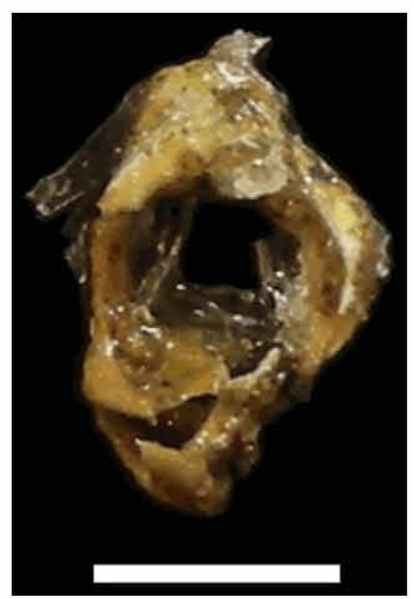

Figure 2. The LF3 stapes. Despite some damage, the asymmetrical configuration of the crura and anteriorly skewed orientation of the head can be appreciated. Scale bar $=2 \mathrm{~mm}$. length provided by Heim (Heim, 1982) (2.7 mm) is considerably greater than the maximum length of the oval window measured in the present study $(2.26 \mathrm{~mm})$. Since the stapes footplate inserts into the oval window, its dimensions should be slightly smaller than that of the oval window. Measurement of these two parameters in a recent human sample (see below) suggests that the linear dimensions of the stapes footplate are about $95 \%$ those of the oval window. This would predict a footplate length of $2.15 \mathrm{~mm}$ for LF3, considerably smaller than the $2.7 \mathrm{~mm}$ estimate of Heim (1982).

Similarly, the value for the area of the footplate provided by Masali et al. (1991) $\left(3.3 \mathrm{~mm}^{2}\right)$ is considerably larger than that estimated from the size of the oval window. The measured area of the oval window in LF3 in the present study is $2.70 \mathrm{~mm}^{2}$. Comparison of the size of the oval window with the stapes footplate in a recent human sample (see below) suggests the area of the stapes footplate is about $90 \%$ that of the oval window. This would predict a stapes footplate area of $2.43 \mathrm{~mm}^{2}$ for LF3, considerably smaller than the $3.3 \mathrm{~mm}^{2}$ estimate of Masali et al. (1991). Taken together, the oval window dimensions clearly indicate a smaller stapes footplate than the values published by both Heim and Masali. Importantly, this revised estimate of footplate area in LF3 is very similar to the values in two other individuals from the same site.

In contrast to the malleus and stapes, the incus is complete and well preserved (Fig. 3). Microscopic examination reveals the tip of the long process is intact, and this bone presents no complications with assessing its morphology and metric dimensions. Table 1 provides the final list of measurements that should be considered reliable on all of the LF3 ossicles. The final values are based on those measured in the present study as well as a careful consideration of previously published data, including that of Heim (1982).

\section{Comparative sample}

The early formation of the ear ossicles means that the adult dimensions are already reached early in ontogeny, and the dimensions of LF3 can thus be compared with both juvenile and adult specimens. The comparative samples (Table 2 ) comprise the vast majority of Neandertal and fossil $H$. sapiens ear ossicles known to date. In most cases the original specimens were studied, and this was complemented with a careful selection of metric data drawn from the literature to ensure that all measurements conform to the protocol outlined below. Many of these specimens were used in a previous study where details of the data collection are provided (Quam and Rak, 2008). In addition, the original ear ossicles of the Middle Paleolithic H. sapiens individual from Darra-i-Kur and the stapes of the Subalyuk 2 Neandertal were recently studied, and the

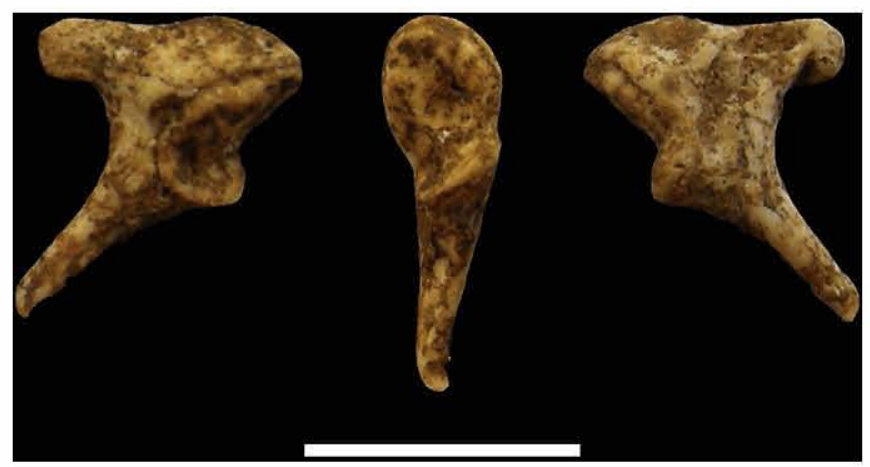

Figure 3. The LF3 incus in (from left to right) lateral, anterior and medial views. Note the closed angle between the processes, a depression on the medial surface of the body and the presence of a notch in the inferior margin of the short process. Scale bar $=5 \mathrm{~mm}$. 
Table 1

Metric dimensions in the La Ferrassie 3 ear ossicles.

\begin{tabular}{|c|c|c|c|c|c|c|c|}
\hline Measurement & $\begin{array}{l}\text { Present } \\
\text { study }\end{array}$ & Heim (1982) & Masali et al. (1991) & Spoor (2002) & Crevecoeur (2007) & Quam and Rak (2008) & Final value \\
\hline \multicolumn{8}{|l|}{ Malleus } \\
\hline Total length & & 8.3 & & 9.0 & 8.9 & & \\
\hline Manubrium length & 4.89 & & & 4.8 & & & 4.89 \\
\hline Manubrium thickness & 1.26 & & & & & & 1.26 \\
\hline Manubrium arc depth & 0.44 & & & & & & 0.44 \\
\hline Corpus length & & & 6.0 & & & & \\
\hline Head width & 2.92 & & & 2.7 & & & 2.92 \\
\hline Angle between the axes & & & & & & 147.0 & \\
\hline \multicolumn{8}{|l|}{ Incus } \\
\hline Short process length & 4.74 & & & & & 4.86 & 4.74 \\
\hline Long process length & 6.89 & 7.2 & & & & & 6.89 \\
\hline Long process arc depth & 0.40 & & & & & 0.36 & 0.40 \\
\hline Articular facet height & 3.34 & & & & & 3.40 & 3.34 \\
\hline Functional length & 4.08 & & & & & 4.41 & 4.08 \\
\hline Inter-process length & 5.51 & & & & & 5.84 & 5.51 \\
\hline Inter-process arc depth & 1.43 & & & & & 1.46 & 1.43 \\
\hline Angle between the axes & 48.2 & & & & & 52.1 & 48.2 \\
\hline \multicolumn{8}{|l|}{ Stapes } \\
\hline Total height & & 3.0 & & & & & 3.00 \\
\hline Head height & 0.92 & & & & & & 0.92 \\
\hline Posterior crus length & & & 3.4 & & & & 3.40 \\
\hline Anterior crus length & & & 2.7 & & & & 2.70 \\
\hline Footplate length & & 2.7 & & & & & \\
\hline Measured footplate area & 2.43 & & 3.3 & & & & 2.43 \\
\hline
\end{tabular}

All values in $\mathrm{mm}$, except angles between the axes (degrees) and footplate area $\left(\mathrm{mm}^{2}\right.$ )

Only measurements that follow the protocols outlined by Masali (1964) and Quam and Rak (2008) are considered.

Values are attributed to the original publication source only.

Table 2

Comparative sample of ear ossicles used in the present study.

\begin{tabular}{|c|c|c|c|c|c|}
\hline Specimen/group & Malleus & Incus & Stapes & Oval window & Source \\
\hline \multicolumn{6}{|c|}{ Middle Pleistocene Europe } \\
\hline Biache-Saint-Vaast 1 & $\mathrm{x}$ & $\mathrm{x}$ & & & $\begin{array}{l}\text { Lisonek and Trinkaus (2006); } \\
\text { Crevecouer (2007) }\end{array}$ \\
\hline AT-84 & & & & $\mathrm{X}$ & Martínez et al. (2004) \\
\hline AT -421 & & & & $\mathrm{x}$ & Martínez et al. (2004) \\
\hline AT-667 (Cranium 5) & & & $\mathrm{X}$ & $\mathrm{X}$ & Martínez et al. (2004) \\
\hline AT- $-3746+3747$ & $\mathrm{x}$ & $\mathrm{x}$ & & & Martínez et al. (2004) \\
\hline \multicolumn{6}{|l|}{ Neandertals } \\
\hline$\overline{\text { La Ferrassie } 3}$ & $\mathrm{X}$ & $\mathrm{X}$ & $\mathrm{X}$ & $\mathrm{x}$ & Original specimen \\
\hline Subalyuk 2 & & & $\mathrm{x}$ & & Original specimen \\
\hline Amud 7 & & $\mathrm{X}$ & & & Original specimen \\
\hline Le Moustier 1 & & $\mathrm{X}$ & & & Ponce de León et al. (1999) \\
\hline La Ferrassie 4 bis & & & & $\mathrm{X}$ & Original specimen \\
\hline La Ferrassie 5 & & & & $\mathrm{X}$ & Original specimen \\
\hline Arcy-sur-Cure & & & & $\mathrm{X}$ & Original specimen \\
\hline Kebara 1 & & & & $\mathrm{x}$ & Original specimen \\
\hline \multicolumn{6}{|l|}{ Fossil H. sapiens } \\
\hline$\overline{\text { Qafzeh } 3}$ & & & & $\mathrm{X}$ & Original specimen \\
\hline Qafzeh 11 & $\mathrm{X}$ & $\mathrm{X}$ & & $\mathrm{X}$ & Original specimen \\
\hline Qafzeh 12 & $\mathrm{X}$ & $\mathrm{x}$ & & $\mathrm{x}$ & Original specimen \\
\hline Qafzeh 13 & & & & $\mathrm{X}$ & Original specimen \\
\hline Qafzeh 15 & $\mathrm{X}$ & $\mathrm{X}$ & & & Original specimen \\
\hline Qafzeh 21 & & $\mathrm{X}$ & & $\mathrm{x}$ & Original specimen \\
\hline Skhul 1 & & & & $\mathrm{x}$ & Original specimen \\
\hline Border Cave 3 & & & & $\mathrm{X}$ & Original specimen \\
\hline Darra-i-Kur & $\mathrm{X}$ & $\mathrm{X}$ & $\mathrm{x}$ & & Original specimen \\
\hline Nazlet Khater 2 & $\mathrm{X}$ & & & & Crevecouer (2007) \\
\hline Dolni Vestonice 14 & $\mathrm{x}$ & $\mathrm{x}$ & & & $\begin{array}{l}\text { Lisonek and Trinkaus (2006); } \\
\text { Quam and Rak (2008) }\end{array}$ \\
\hline Dolni Vestonice 15 & & $\mathrm{x}$ & & & $\begin{array}{l}\text { Lisonek and Trinkaus (2006); } \\
\text { Quam and Rak (2008) }\end{array}$ \\
\hline Cro-Magnon 2 & & & & $\mathrm{x}$ & Original specimen \\
\hline Lagar Velho 1 & $\mathrm{x}$ & $\mathrm{X}$ & & & Original specimen \\
\hline Parpalló 1 & & & & $\mathrm{x}$ & Original specimen \\
\hline Recent $H$. sapiens & $(n=43)$ & $(n=43)$ & $(n=40)$ & & Original specimens \\
\hline
\end{tabular}


data for these individuals are included in the present study. A number of fossil specimens do not preserve ear ossicles, but the oval window can be measured to provide an estimate of the size of the stapes footplate. We have also studied a sample of recent human ear ossicles removed during cadaveric dissection in gross anatomy instruction at the New York Chiropractic College in Seneca Falls, New York (USA). This sample is comprised of individuals of known sex and race, ranging in age from 51 to 100 years old. The individuals included in the present study were selected based on a criterion of maximizing the number of individuals that preserve all three bones.

\section{Morphological features}

The expression of several morphological features in the ear ossicles was assessed in LF3 and the comparative samples. Several features described by Heim (1982) in the LF3 ossicles have been cited by subsequent authors as potential derived Neandertal features (Maureille, 2002; Crevecoeur, 2007; Quam and Rak, 2008). Among these are a relatively straight malleus manubrium and incus long process, a flatter incus body, asymmetrical stapedial crura and an anteriorly skewed stapedial head. Importantly, all of these features can be assessed in the LF3 ossicles in their current state of preservation. Although the functional significance of many of these features (if any) is not clear, the tight genetic control over the development of the ear ossicles means that variation in the expression of these features can generally be taken to reflect genetic differentiation between populations, the soundest basis for drawing phylogenetic inferences (Lieberman, 1995).

\section{Measurement definitions and protocol}

Numerous previous studies on the auditory ossicles have relied on different techniques to collect metric data and have introduced a variety of measurement definitions (Heron, 1923; Kirikae, 1960; Bouchet and Giraud, 1968; Blumer et al., 1982; Mutaw, 1986; Siori et al., 1995). Despite some variation in methodology, the reported mean sizes of the ossicles are generally similar across studies (Arensburg et al., 1981), suggesting that measurement error, when controlled for, is not a significant source of variation in the reported dimensions of the auditory ossicles. The two most influential studies that introduced standardized techniques and measurement definitions for the ossicles are those of Masali (1964) and Arensburg et al. (1981), and several subsequent studies of fossil hominin ear ossicles have followed one or the other of these protocols (Spoor, 2002; Lisonek and Trinkaus, 2006; Quam, 2006; Crevecoeur, 2007; Quam and Rak, 2008).

The original LF3 specimens were studied by one of us (RMQ). The specimens were examined under a standard light microscope to evaluate the present state of preservation and to aid in assessing some morphological features. For measurement purposes, scaled photographs were taken of the ossicles using a digital camera and measured on a computer using the Photoshop ${ }^{\mathrm{TM}}$ software program. The malleus was positioned so that the manubrium was placed flat on the surface of the table with the posterior aspect of the bone (exposing the articular facet) facing the camera lens. The incus was positioned so that the long and short processes were flat on the surface of the table with the lateral aspect of the bone (exposing the lower-most margin of the articular facet) facing the camera lens. The stapes was placed flat on the surface of the table with the superior aspect of the bone facing the camera lens. In this position, the superiormost margin of the obturator foramen is exposed. For calibration purposes, a $10 \mathrm{~mm}$ scale was placed next to the bone on the surface of the table. For those specimens that preserved a stapes footplate, the bone was inverted so the footplate was facing the camera lens. The long axis of the footplate was oriented perpendicular to that of the camera lens, resulting in the maximum exposure of the footplate, and a $10 \mathrm{~mm}$ scale was placed at the same distance from the camera as the stapes footplate.

With a few exceptions, we have generally relied on the measurements defined by Masali (1964). A detailed account of the measurement definitions for the malleus and incus (including some inconsistencies in measurement definitions in previous studies) has been published previously (Quam and Rak, 2008) and is followed here. The current state of preservation of the LF3 stapes limits the metric data that can be collected on this specimen. The measurement definitions for the stapes variables are provided here and in Fig. 4. The total stapes height is the maximum height from the lower margin of the footplate to the tip of the head, taken perpendicular to the long axis of the footplate. The length of the anterior crus is the maximum distance from the antero-superior corner of the footplate to the tip of the head. The length of the posterior crus is the maximum distance from the postero-superior corner of the footplate to the tip of the head. The head height is the minimum distance between the superior margin of the obturator foramen and the top of the head. Footplate area is the directly measured area of the stapes footplate.

The oval window area was measured following similar procedures as for the auditory ossicles. The oval window was oriented so that the maximum area was exposed and the long axis of the oval window was perpendicular to that of the camera lens. A scale was included in the digital photo for calibration purposes and was placed at the same distance from the camera lens as the oval window itself. The photos were then transferred to the computer and measured using the Photoshop ${ }^{\mathrm{TM}}$ software program. A similar measurement protocol has been used in previous studies (Coleman and Ross, 2004; Martínez et al., 2004; Coleman and Colbert, 2010).

\section{Estimating stapes footplate area}

The footplate area in the LF3 stapes was estimated from the dimensions of the preserved oval window on the medial wall of the tympanic cavity. This approach has been used previously in other studies (Martínez et al., 2004; Coleman and Colbert, 2010), and a close correspondence $\left(r^{2}=0.961\right)$ has been found between the size of these two structures across primates (Coleman and Ross, 2004) since the stapes footplate inserts into the oval window. The stapes footplate is slightly smaller than the oval window since it is held in place by the annular ligament, which attaches to the

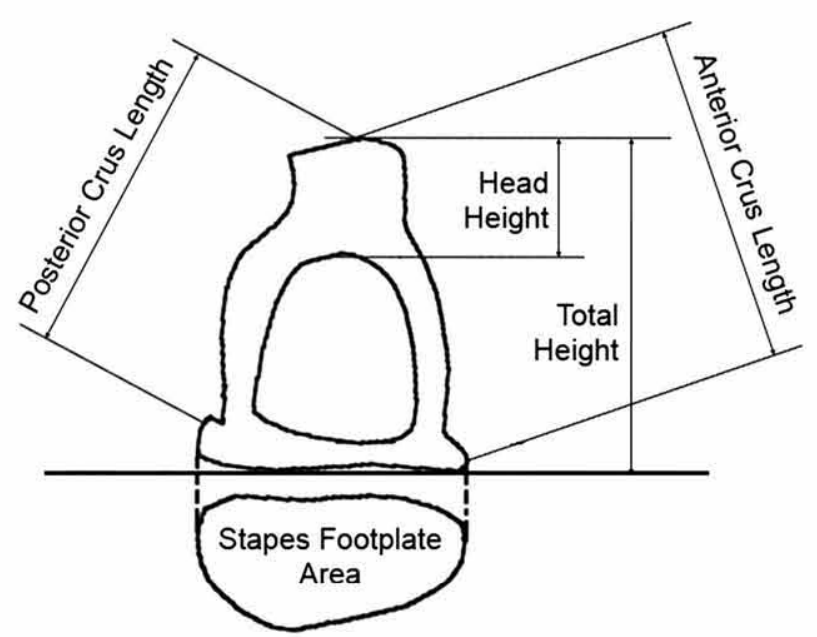

Figure 4. Definitions of the stapes measurements. See text for additional information. 
circumference of the footplate. To account for this size discrepancy, we have measured the stapes footplate area and oval window area in a sample of 29 neonatal individuals of known sex and race, all aged between six months intrauterine and 14 months postnatal, deriving from the Johns Hopkins Fetal Collection housed at the Cleveland Museum of Natural History (USA). Importantly, both dimensions were measured in each individual. The length and width of the stapes footplate was found to be approximately $95 \%$ of the value of the length and width of the oval window. Similarly, the measured area of the stapes footplate was found to correspond to approximately $90 \%$ of the value of the area of the oval window. A similar ratio was also found to characterize the Middle Pleistocene humans from the Sima de los Huesos (SH) site in the Sierra de Atapuerca (Martínez et al., 2004).

\section{Statistical analysis}

Statistical analysis of the ossicular variables includes univariate and multivariate approaches. In addition to descriptive statistics, correlations between ossicular variables within the recent human sample were explored and significant correlations $(p<0.05)$ are discussed when relevant to interpreting the fossil specimens. Correlations above $r>0.7$ were considered high. Subsequently, principal components analysis (PCA) was undertaken for the incus and stapes. The incus is the only bone that is complete and wellpreserved, and all relevant dimensions could be used. Although the stapes is damaged, the few preserved measurements do largely capture the overall dimensions of this bone. In contrast, the preserved malleus measurements are largely restricted to the manubrium, limiting the utility of a multivariate analysis. PCA reduces the number of variables to a smaller number of components whose constituent variables can then be analyzed. By default, PCA generates the same number of components as variables in the analysis, but only those components that yield eigenvalues $>1.0$ can be considered to explain more variation than the individual variables in isolation (Kachigan, 1991). Factor loadings of $>0.7$ for the individual variables, indicating their correlation with the principal component, were generally considered high.

\section{The La Ferrassie 3 ear ossicles}

\section{Malleus (Fig. 1)}

The description of the malleus morphology refers to the bone when oriented in anatomical position in the tympanic cavity, with the manubrium tip placed inferiorly, the manubrium itself laterally, the head medially and superiorly and the articular facet posteriorly.
The lateral margin of the manubrium is curved, and shows a laterally inflected tip. In contrast, the medial margin is relatively straight and the manubrium increases in thickness from the tip to the neck. The lateral process is well-developed and protrudes laterally. The medial surface of the malleus head shows some erosion of the bone near the margin of the articular facet. This could be attributed to an erosive episode of otitis media, but could equally be taphonomic in nature. The head shows a prominent protrusion antero-superiorly, opposite the articular facet. Just below this is a depressed area filled with sediment, on the anterior aspect of the head and neck. The articular facet itself is separated from the malleus head by a groove. The groove on the lateral neck described in Qafzeh 11 does not appear to be present in LF3. It is not possible to discern whether a prominent crest was present on the posterior neck since the specimen is broken just at the level where this crest would be. Nor is it possible to tell whether an anterior (gracile) process was present in the current state of preservation.

Heim (1982) described the LF3 malleus manubrium as relatively straight with a well-developed lateral process. The description of the manubrium as straight seems to be an inference drawn largely from the published photo of the incorrectly reconstructed specimen. Examination of the original specimen makes it clear that the manubrium shows a curved lateral margin with a laterally inflected tip. This same morphology is found in $80 \%$ of fossil H. sapiens specimens where the manubrium tip is preserved (Quam and Rak, 2008). A curved manubrium is also the common condition in recent $H$. sapiens, being present in $66.2 \%$ of our recent human sample (Quam and Rak, 2008). The lateral process in LF3 is well-developed, but is clearly encompassed within the normal range of variation seen in both fossil and recent $H$. sapiens. Among the fossil $H$. sapiens specimens, only the Lagar Velho 1 individual apparently lacks a lateral process, and this is an uncommon variant in recent humans as well. The lateral process in the human malleus is embedded in the superior fibers of the tympanic membrane. However, it is not clear that degree of development of the lateral process in LF3 implies a greater protrusion of the tympanic membrane in Neandertals, as suggested by Heim (1982).

Heim asserted that the LF3 malleus was slightly longer with a larger head and more open angle between the manubrium and head/neck than in $H$. sapiens. The total length and angle of the axes cannot be assessed in the LF3 malleus. The manubrium length in LF3 $(4.89 \mathrm{~mm})$ is slightly shorter than the Middle Pleistocene AT3746 specimen but longer than all but one of the fossil $H$. sapiens individuals (Darra-i-Kur) (Table 3). The value in LF3 is, however, very close to the mean value in our recent $H$. sapiens sample. In contrast, the manubrium thickness $(1.26 \mathrm{~mm})$ is quite high, falling above the recent $H$. sapiens range of variation and only being

Table 3

Malleus dimensions in the La Ferrassie 3 Neandertal and Pleistocene and recent humans.

\begin{tabular}{|c|c|c|c|c|c|}
\hline Specimen/sample & $\begin{array}{l}\text { Manubrium } \\
\text { length (mm) }\end{array}$ & $\begin{array}{c}\text { Manubrium } \\
\text { thickness (mm) }\end{array}$ & $\begin{array}{c}\text { Manubrium arc } \\
\text { depth (mm) }\end{array}$ & $\begin{array}{c}\text { Head } \\
\text { width (mm) }\end{array}$ & $\begin{array}{c}\text { Manubrium } \\
\text { robusticity index }\end{array}$ \\
\hline La Ferrassie 3 & 4.89 & 1.26 & 0.44 & 2.92 & 25.8 \\
\hline AT -3746 & 5.16 & & & & \\
\hline Biache-Saint-Vaast 1 & $>4.10$ & & & 2.70 & \\
\hline Qafzeh 11 & & & & 2.41 & \\
\hline Qafzeh 12 & 4.02 & 1.11 & 0.33 & 2.62 & 27.4 \\
\hline Qafzeh 15 & 4.48 & 1.02 & 0.28 & 2.44 & 22.3 \\
\hline Darra-i-Kur & 5.02 & 1.34 & 0.40 & 2.50 & 26.7 \\
\hline Dolni Vestonice 14 & 4.60 & 0.87 & 0.14 & 2.50 & 18.9 \\
\hline Nazlet Khater 2 & 4.67 & 0.90 & 0.27 & 2.55 & 19.3 \\
\hline Lagar Velho 1 (left) & 4.38 & 0.81 & 0.19 & 2.33 & 18.5 \\
\hline Fossil H. sapiens (mean \pm s.d.) & $4.53 \pm 0.33$ & $1.01 \pm 0.20$ & $0.27 \pm 0.09$ & $2.48 \pm 0.10$ & $22.2 \pm 4.0$ \\
\hline Fossil H. sapiens range ( $\mathrm{n}$ ) & $4.02-5.02(6)$ & $0.81-1.34(6)$ & $0.14-0.40(6)$ & $2.33-2.62(7)$ & $18.5-27.4(6)$ \\
\hline Recent $H$. sapiens (mean \pm s.d.) & $4.94 \pm 0.31$ & $1.00 \pm 0.09$ & $0.33 \pm 0.15$ & $2.43 \pm 0.17$ & $20.3 \pm 1.9$ \\
\hline Recent $H$. sapiens range $(n)$ & $4.22-5.59(43)$ & $0.81-1.19(43)$ & $0.05-0.64(43)$ & $2.03-2.79(43)$ & $16.6-25.6(43)$ \\
\hline
\end{tabular}


surpassed by the value in Darra-i-Kur. The resulting robusticity index (25.8) is similarly high, again only being surpassed by two of the fossil $H$. sapiens individuals (Qafzeh 12 and Darra-i-Kur) and falling nearly 2.9 standard deviations (s.d.) above the mean in our recent $H$. sapiens sample. The arc depth of the manubrium is a measure of the degree of curvature of the lateral margin. The value in LF3 $(0.44 \mathrm{~mm})$ is higher than all of the fossil $H$. sapiens individuals but is within 1 s.d. above the recent $H$. sapiens mean, indicating a curved lateral margin of the manubrium in LF3. The head width in LF3 $(2.92 \mathrm{~mm})$ is larger than the value provided by Heim (1982), falling above the head width in the Middle Pleistocene Biache 1 specimen and outside the range of variation in both the fossil and recent $H$. sapiens samples, confirming that a large head size characterizes LF3.

Among the few preserved malleus dimensions, the thickness and curvature (arc depth) of the manubrium were not correlated with its length within the recent $H$. sapiens sample. However, moderate positive $(r=0.45)$ and negative $(r=-0.39)$ correlations were found between the manubrium length and head width and robusticity index, respectively. The robusticity index shows a much stronger correlation $(r=0.77)$ with the manubrium thickness, indicating that the values for this index are driven largely by variation in thickness.

\section{Incus (Fig. 3)}

The description of the incus morphology refers to the bone when oriented in anatomical position in the tympanic cavity, with the tip of the long process placed inferiorly and angled posteriorly, the short process placed superiorly and protruding posteriorly, the articular facet facing anteriorly and the lowermost margin of the articular facet facing laterally to articulate with the malleus head. The LF3 incus is complete and well-preserved. The contour of the superior margin of the short process is concave and the tip is thick supero-inferiorly. On the medial aspect of the short process, a clear notch is present along the lower margin. There is a depressed area in the central portion of the medial aspect of the body, just posterior to the articular facet. The articular facet itself is separated from the surrounding bone by a groove, particularly visible in lateral view. The articular facet shows a skewed orientation, with the inferior margin being lower on the lateral aspect, where it articulates with the malleus head, than on the medial. The anterior margin of the long process is relatively straight, particularly in lateral view, but the tip does deflect medially for articulation with the stapes head.

Heim (1982) suggested that the long process of the incus in LF3 is relatively straight and thin when compared with $H$. sapiens, while the short process does not show a notch in its lower border and the body is slightly flatter than in $H$. sapiens. The long process in LF3 does show a very straight anterior border (Fig. 3) and resembles the condition seen in both the Amud 7 and Le Moustier 1 Neandertals. Nevertheless, some variation among the fossil and recent $H$. sapiens samples is also present. Both Qafzeh 11 and Dolni Vestonice 15 show a straight long process and this condition is found in just under $25 \%$ of recent $H$. sapiens (Quam and Rak, 2008). The lower margin of the short process shows a clear notch in medial view (contra Heim). This is a well-known anatomical variant in the incudi of fossil and recent $H$. sapiens (Arensburg and Nathan, 1971, 1972), and it is also found in both the Amud 7 and Le Moustier 1 Neandertals (Quam and Rak, 2008). The form of the short process tip is variable in fossil and recent $H$. sapiens, ranging from a very thick, bulbous appearance to a slender, tapering point. This range of variation is seen among the four incudi from Qafzeh (Quam and Rak, 2008), but the tip of the short process in all three known Neandertal incudi is thick supero-inferiorly with a rounded posterior margin. The body of the LF3 incus also shows a deeply excavated depression on its medial surface (Fig. 3), resembling Amud 7 in this regard. The majority of fossil and recent $H$. sapiens specimens also show a depression on the medial surface of the incus body. In both Qafzeh 12 and 15 and $16 \%$ of recent $H$. sapiens, this depression is as deep as in LF3 (Quam and Rak, 2008). In general, the morphological details of the incus in Neandertals seem less variable than in $H$. sapiens.

The length of the short process in LF3 $(4.74 \mathrm{~mm})$ is slightly shorter than in Amud $7(5.07 \mathrm{~mm}$ ) (Table 4). Nevertheless, LF3 falls within 1 s.d. below the recent $H$. sapiens mean and is nearly identical to the mean value in fossil $H$. sapiens. The long process length in LF3 $(6.89 \mathrm{~mm})$ is clearly shorter than that in Biache 1, but falls between the values of the Amud 7 and Le Moustier 1 Neandertals. However, the values in the three Neandertal individuals are similar

Table 4

Incus dimensions in the La Ferrassie 3 Neandertal and Pleistocene and recent humans.

\begin{tabular}{|c|c|c|c|c|c|c|c|c|c|}
\hline Specimen/sample & $\begin{array}{l}\text { Short } \\
\text { process } \\
\text { length } \\
(\mathrm{mm})\end{array}$ & $\begin{array}{l}\text { Long } \\
\text { process } \\
\text { length } \\
(\mathrm{mm})\end{array}$ & $\begin{array}{l}\text { Functional } \\
\text { length } \\
(\mathrm{mm})\end{array}$ & $\begin{array}{l}\text { Long process } \\
\text { arc depth } \\
\text { (mm) }\end{array}$ & $\begin{array}{c}\text { Articular } \\
\text { facet } \\
\text { height (mm) }\end{array}$ & $\begin{array}{l}\text { Inter-process } \\
\text { length } \\
(\mathrm{mm})\end{array}$ & $\begin{array}{l}\text { Inter-process } \\
\text { arc depth (mm) }\end{array}$ & $\begin{array}{c}\text { Angle } \\
\text { between } \\
\text { the axes } \\
\text { (deg) }\end{array}$ & $\begin{array}{l}\text { Incudal } \\
\text { index }\end{array}$ \\
\hline La Ferrassie 3 & 4.74 & 6.89 & 4.08 & 0.40 & 3.34 & 5.51 & 1.43 & 48.2 & 68.8 \\
\hline AT -3747 & & & 4.33 & & & & & & \\
\hline Biache-Saint-Vaast 1 & & 7.50 & & & & 5.90 & & & \\
\hline Amud 7 & 5.07 & 6.98 & 4.08 & 0.28 & 3.44 & 5.38 & 2.13 & 48.3 & 72.6 \\
\hline Le Moustier 1 & & 6.80 & & & & & & & \\
\hline Qafzeh 11 & 5.07 & 6.94 & 4.05 & 0.30 & 3.42 & 5.95 & 2.00 & 52.4 & 73.1 \\
\hline Qafzeh 12 & 4.70 & 6.73 & 3.84 & 0.43 & 3.26 & 5.85 & 1.30 & 62.0 & 69.8 \\
\hline Qafzeh 15 & 4.64 & 6.34 & 3.57 & 0.35 & 3.30 & 5.29 & 1.60 & 61.7 & 73.2 \\
\hline Qafzeh 21 & 4.55 & 6.47 & 3.93 & 0.44 & 2.87 & 5.52 & 1.46 & 61.7 & 70.3 \\
\hline Darra-i-Kur & 4.78 & 6.75 & 4.46 & 0.63 & 3.26 & 6.23 & 1.84 & 69.2 & 70.8 \\
\hline Dolni Vestonice 14 & 5.50 & 7.10 & 4.11 & 0.56 & 3.35 & 6.60 & 1.75 & 67.3 & 77.5 \\
\hline Dolni Vestonice 15 & 4.10 & 6.40 & 3.89 & 0.35 & 3.15 & 5.50 & 1.35 & 62.6 & 64.1 \\
\hline Lagar Velho 1 & 4.76 & & & & 3.14 & & & 61.5 (est.) & \\
\hline $\begin{array}{l}\text { Fossil H. sapiens } \\
\quad(\text { mean } \pm \text { s.d. })\end{array}$ & $4.76 \pm 0.40$ & $6.68 \pm 0.29$ & $3.98 \pm 0.27$ & $0.44 \pm 0.12$ & $3.22 \pm 0.17$ & $5.85 \pm 0.46$ & $1.61 \pm 0.26$ & $62.4 \pm 5.4$ & $71.3 \pm 4.1$ \\
\hline $\begin{array}{l}\text { Fossil H. sapiens } \\
\text { range }(\mathrm{n})\end{array}$ & $4.10-5.50(8)$ & $6.34-7.10(7)$ & $3.57-4.46(7)$ & $0.30-0.63(7)$ & $2.87-3.42(7)$ & $5.29-6.60(7)$ & $1.30-2.00(7)$ & $52.4-69.2(8)$ & $64.1-77.5(7)$ \\
\hline $\begin{array}{l}\text { Recent } H \text { sapiens } \\
\quad(\text { mean } \pm \text { s.d. })\end{array}$ & $5.07 \pm 0.37$ & $6.83 \pm 0.32$ & $4.00 \pm 0.21$ & $0.56 \pm 0.14$ & $3.00 \pm 0.19$ & $6.18 \pm 0.34$ & $1.66 \pm 0.21$ & $64.0 \pm 4.7$ & $74.3 \pm 4.9$ \\
\hline $\begin{array}{l}\text { Recent } H \text {. sapiens } \\
\quad \text { range }(\mathrm{n})\end{array}$ & $4.02-5.86(41)$ & $6.17-7.59(43)$ & $3.61-4.46(42)$ & $0.25-0.80(43)$ & $2.60-3.41(42)$ & $5.61-7.44(41)$ & $1.18-1.95(41)$ & $56.6-75.6(41)$ & $59.2-84.8(41)$ \\
\hline
\end{tabular}


to the fossil and recent $H$. sapiens means, and the incudal index, comparing the lengths of the processes, does not seem to vary along taxonomic lines. Thus, there appears to be little evidence for a difference in the absolute or relative lengths of the processes between Neandertals and $H$. sapiens.

The articular facet height in LF3 $(3.34 \mathrm{~mm})$ is only slightly shorter than in Amud 7. Both Neandertal specimens fall either toward the upper end (LF3) or outside of (Amud 7) the range of variation in fossil and recent $H$. sapiens. The arc depth of the long process in LF3 $(0.40 \mathrm{~mm})$, a measure of the curvature of the anterior margin, is slightly higher than in Amud 7 but is lower than in all but two of the fossil $H$. sapiens individuals. The value in LF3 also falls more than 1 s.d. below the recent $H$. sapiens mean (Table 4 ), clearly indicating a straighter anterior margin. The angle between the long and short processes in LF3 $\left(48.2^{\circ}\right)$ is nearly identical to that in Amud $7\left(48.3^{\circ}\right)$, and both Neandertals fall below the range of variation in the fossil and recent $H$. sapiens samples, indicating a more closed angle of the incus. In relation to this, the inter-process length is shorter in both Neandertal specimens as well falling below the lower limit of the recent $H$. sapiens range of variation but similar to two fossil $H$. sapiens individuals. Interestingly, the longer long process in Biache 1 results in a wider inter-process length, more similar to the values in $H$. sapiens. The inter-process arc depth in LF3 is much shallower than Amud 7 but falls within the range of variation in both fossil and recent $H$. sapiens.

There is only a moderate correlation $(r=0.50)$ between the lengths of the long and short processes within the recent $H$. sapiens sample. In contrast, values of the incudal index seem to be largely driven by variation in the short process length, given the strong correlation $(r=0.78)$ between these two variables. The long process length is only moderately correlated with the articular facet height $(r=0.50)$ but shows stronger correlations with the functional length $(r=0.73)$ and the inter-process length $(r=0.80)$. Increases in the distance between the long and short processes length, then, seem to be driven primarily by increases in the long process length and secondarily by variation in the angle between the axes $(r=0.60)$ and the curvature of the long process $(r=0.52)$.

Principal components analysis was carried out with seven linear dimensions and one angular variable, and the first three principal components yielded eigenvalues $>1.0$ (Table 5 ). The first two principal components explain $66.9 \%$ of the total variance (Fig. 5). The inter-process length, long process length, functional length and short process length all show high factor loadings on the first component. The first component largely seems to reflect size differences, with higher scores being associated with incudi that have longer long and short processes. The Neandertals are not distinguished from the fossil or recent $H$. sapiens along the first component. The angle between the axes and the long process arc depth show strong and moderate negative factor loadings on the second component, and the articular facet height shows

Table 5

Results of the principal components analysis of incus variables.

\begin{tabular}{lccr}
\hline & Factor 1 & Factor 2 & Factor 3 \\
\hline Eigenvalue & 3.39 & 1.97 & 1.10 \\
\% Total variance & $42.3 \%$ & $24.6 \%$ & $13.7 \%$ \\
Variable factor loadings & & & \\
Short process length & 0.707 & 0.223 & -0.353 \\
Articular facet height & 0.218 & 0.601 & 0.673 \\
Long process length & 0.848 & 0.322 & 0.225 \\
Angle between the axes & 0.443 & -0.823 & -0.010 \\
Functional length & 0.748 & 0.244 & 0.070 \\
Long process arc depth & 0.620 & -0.584 & 0.036 \\
Inter-process length & 0.911 & -0.258 & 0.113 \\
Inter-process arc depth & 0.390 & 0.558 & -0.670 \\
\hline
\end{tabular}

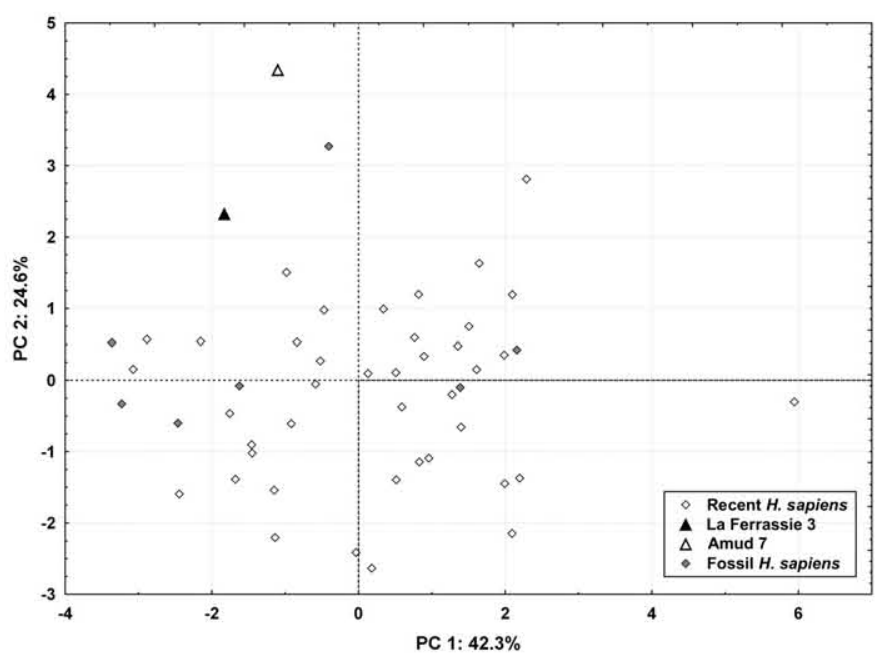

Figure 5. Scatterplot distribution of the first and second principal components based on the incus variables. The first component largely reflects size differences, with higher values indicating longer short and long processes, and does not effectively discriminate between taxa. The single recent $H$. sapiens outlier is the largest individual in the sample. The second component reflects variation in the angle of the axes, the articular facet height and the curvature of the long process. Higher values along the second component reflect a more closed angle, a taller articular facet and straighter long processes. Here the two Neandertal individuals are clearly separated from both fossil and recent $H$. sapiens, with the exception of Qafzeh 11 .

a moderate positive factor loading. Higher values along the second component, then, are associated with more closed angles between the axes, straighter long processes and taller articular facets. Here the two Neandertal specimens are clearly separated from the fossil and recent $H$. sapiens samples. One fossil $H$. sapiens individual (Qafzeh 11) does, however, fall close to the two Neandertals (Fig. 5). This specimen shows the lowest angle between the axes and tallest articular facet of any $H$. sapiens individual, fossil or recent, as well as a very straight long process. The third principal component explains an additional $13.7 \%$ of the total variance but does not separate the specimens along taxonomic lines.

\section{Middle ear lever ratio}

The functional length of the incudal long process in LF3 $(4.08 \mathrm{~mm})$ is slightly shorter than in the Middle Pleistocene specimen AT-3747, but is identical to that in Amud 7 and close to the fossil and recent $H$. sapiens means. Comparison of the incudal functional length with the mallear manubrium length yields the lever ratio of the middle ear, an important physiological variable in modeling audition (Martínez et al., 2004, in press; Quam et al., 2012). The lever ratio in LF3 (119.9) (Table 6) is nearly identical to

Table 6

The malleus/incus lever ratio in La Ferrassie 3 and Pleistocene and recent hominins.

\begin{tabular}{lccc}
\hline Specimen/sample & $\begin{array}{c}\text { Malleus functional } \\
\text { length (mm) }\end{array}$ & $\begin{array}{c}\text { Incus functional } \\
\text { length (mm) }\end{array}$ & $\begin{array}{c}\text { Malleus/incus } \\
\text { lever ratio }\end{array}$ \\
\hline La Ferrassie 3 & 4.89 & 4.08 & 119.9 \\
AT-3746 + 3747 & 5.16 & 4.33 & 119.2 \\
Qafzeh 12 & 4.02 & 3.84 & 104.7 \\
Qafzeh 15 & 4.48 & 3.57 & 125.5 \\
Darra-i-Kur & 5.02 & 4.46 & 112.6 \\
Dolni Vestonice 14 & 4.60 & 4.11 & 111.9 \\
Recent H. sapiens & $4.94 \pm 0.31$ & $4.00 \pm 0.21$ & $123.4 \pm 8.5$ \\
$\quad$ (mean \pm s.d.) & & & \\
Recent H. sapiens & $4.22-5.59(43)$ & $3.61-4.46(42)$ & $101.9-138.9(42)$ \\
range $(n)$ & & & \\
\hline
\end{tabular}

${ }^{\mathrm{a}}$ Lever ratio $=($ malleus functional length/incus functional length $) \times 100$. 


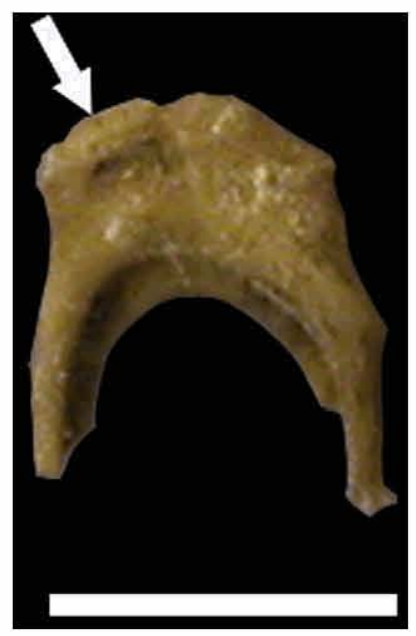

Figure 6. The Subalyuk 2 stapes. Despite some obvious signs of pathology, the head (arrow) is clearly anteriorly skewed, like in LF3. Scale bar $=2 \mathrm{~mm}$.

that calculated for the Middle Pleistocene specimens AT-3746/3747 (119.2). Although both of these specimens fall toward the upper end of the fossil $H$. sapiens range of variation, they are close to the recent $H$. sapiens mean (123.4). Thus, there appears to be little difference in the lever ratio between Neandertals and $H$. sapiens.

\section{Stapes (Fig. 2)}

The description of the stapes morphology refers to the bone when oriented in anatomical position in the tympanic cavity, with the head placed laterally to articulate with the tip of the incus long crus, the crura located anteriorly and posteriorly and the footplate located medially with its long axis oriented antero-posteriorly. The current state of preservation limits the morphological observations that can be made on this specimen. Heim (1982) described the LF3 stapes as showing a pronounced asymmetry between the shorter anterior crus and the longer and more curved posterior crus. In addition, the head of the stapes was described as skewed anteriorly and the crura as thicker in LF3. The footplate was described as 'réniforme', or kidney-shaped, like in H. sapiens.

The combination of a pronounced asymmetry between the anterior and posterior crura and an anteriorly skewed head are evident in the published photo of the complete stapes (Heim, 1982). In addition, both of these features can be appreciated in the LF3 stapes, even given its current state of preservation. The Subalyuk 2 Neandertal infant also preserves a partial stapes, and this specimen is described as showing asymmetrical crura (Arensburg et al., 1996; Pap et al., 1996). Although the head on this specimen shows some signs of pathology, examination of the original fossil (Fig. 6) reveals that it clearly shows an anteriorly skewed head (contra Arensburg et al., 1996). In addition, asymmetrical crura are also said to characterize the stapes in the recently rediscovered Le Moustier 2 Neandertal infant (Maureille, 2002). While the stapedial head normally occupies a central position $(65.4 \%$ ) in recent $H$. sapiens, resting atop both crura equally, an anterior orientation (32.7\%) is a common variant (Quam, 2006). Thus, while some variation in the orientation of the stapedial head characterizes recent $H$. sapiens, the Neandertals show a consistent anatomical pattern.

The height of the LF3 stapes $(3.00 \mathrm{~mm})$ is slightly taller than that estimated for the Subalyuk 2 Neandertal but is shorter than the Darra-i-Kur specimen and falls more than 2 s.d. below the recent $H$. sapiens mean value (Table 7). Thus, Heim's (1982) assertion that the Neandertals have a slightly smaller stapes would appear to be correct. The head height in LF3 is similar to that in Subalyuk 2 but again falls toward the lower end of the recent $H$. sapiens range of variation, and the relative head height in all of the fossil specimens falls below the recent $H$. sapiens mean. Both Neandertal individuals have an anterior crus that is much shorter than the posterior crus, while in recent $H$. sapiens the lengths of the crura are much more similar. The resulting crural index in both Neandertal individuals falls below the recent $H$. sapiens range of variation, consistent with the highly asymmetrical configuration of the crura in Neandertals.

The stapes footplate in LF3 is damaged and cannot be measured directly. However, the area of the footplate can be estimated from the preserved oval window on the medial wall of the tympanic cavity. The size of the oval window in LF3 $\left(2.70 \mathrm{~mm}^{2}\right.$ ) (Table 8$)$ is consistent with an estimated stapes footplate area of $2.43 \mathrm{~mm}^{2}$. This value is identical or very close to that measured in two other specimens from La Ferrassie and is within 1 s.d. of the Neandertal mean. It is slightly smaller than the three Middle Pleistocene Atapuerca ( $\mathrm{SH}$ ) individuals but well below the lower limit of the range of variation in fossil and recent $H$. sapiens. The oval window index in LF3 (54.0), comparing the length and width of the oval window, is nearly identical to the Neandertal mean (54.7) but is higher than all but two of the fossil $H$. sapiens individuals and is more than 2 s.d. above the recent $H$. sapiens mean based on the stapes footplate. Thus, although the stapes footplate is 'kidney-shaped', like in $H$. sapiens, Neandertal specimens show a slightly wider oval window, and hence stapes footplate.

The total stapes height is strongly correlated with the lengths of the anterior $(r=0.83)$ and posterior $(r=0.84)$ crura. While a moderate correlation is also found with head height $(r=0.59)$, no correlation with the relative head height was found. Thus, relative head height is driven primarily by variation in the height of the stapes head $(r=0.91)$. The length and width of the footplate are only weakly correlated with one another $(r=0.39)$ but show strong correlations $(0.73<r<0.83$, respectively) with the measured footplate area. The footplate index is only weakly correlated with the measured area $(r=0.37)$, and variation in this index seems to be

Table 7

Stapes dimensions in the La Ferrassie 3 Neandertal and Pleistocene and recent humans.

\begin{tabular}{|c|c|c|c|c|c|c|}
\hline Specimen/sample & $\begin{array}{c}\text { Total } \\
\text { height (mm) }\end{array}$ & $\begin{array}{c}\text { Head } \\
\text { height (mm) }\end{array}$ & $\begin{array}{l}\text { Anterior crus } \\
\text { length (mm) }\end{array}$ & $\begin{array}{l}\text { Posterior crus } \\
\text { length (mm) }\end{array}$ & $\begin{array}{l}\text { Crural } \\
\text { index }^{a}\end{array}$ & $\begin{array}{l}\text { Relative head } \\
\text { height }^{\mathrm{b}}\end{array}$ \\
\hline La Ferrassie 3 & 3.00 & 0.92 & 2.70 & 3.40 & 79.4 & 30.7 \\
\hline Subalyuk 2 & 2.70 est. & 0.93 & 2.45 est. & $2.90 \mathrm{est}$ & 84.5 est & $34.4 \mathrm{est}$ \\
\hline Darra-i-Kur & 3.13 & 0.83 & 2.82 & 3.17 & 89.0 & 26.5 \\
\hline $\begin{array}{l}\text { Recent } H \text {. sapiens } \\
\text { (mean } \pm \text { s.d.) }\end{array}$ & $3.44 \pm 0.20$ & $1.21 \pm 0.16$ & $3.40 \pm 0.21$ & $3.35 \pm 0.20$ & $101.6 \pm 5.6$ & $35.2 \pm 3.9$ \\
\hline $\begin{array}{l}\text { Recent } H \text { sapiens } \\
\quad \text { range }(n)\end{array}$ & $2.94-3.87(40)$ & $0.87-1.52(40)$ & $2.94-3.93(40)$ & $2.77-3.72(40)$ & $88.4-108.8(40)$ & $26.3-43.5(40)$ \\
\hline
\end{tabular}

a Crural index $=$ (anterior crus length/posterior crus length $) \times 100$.

b Relative head height $=($ Head height/total height $) \times 100$. 
Table 8

Comparison of oval window dimensions and footplate area in La Ferrassie 3 with Pleistocene and recent humans.

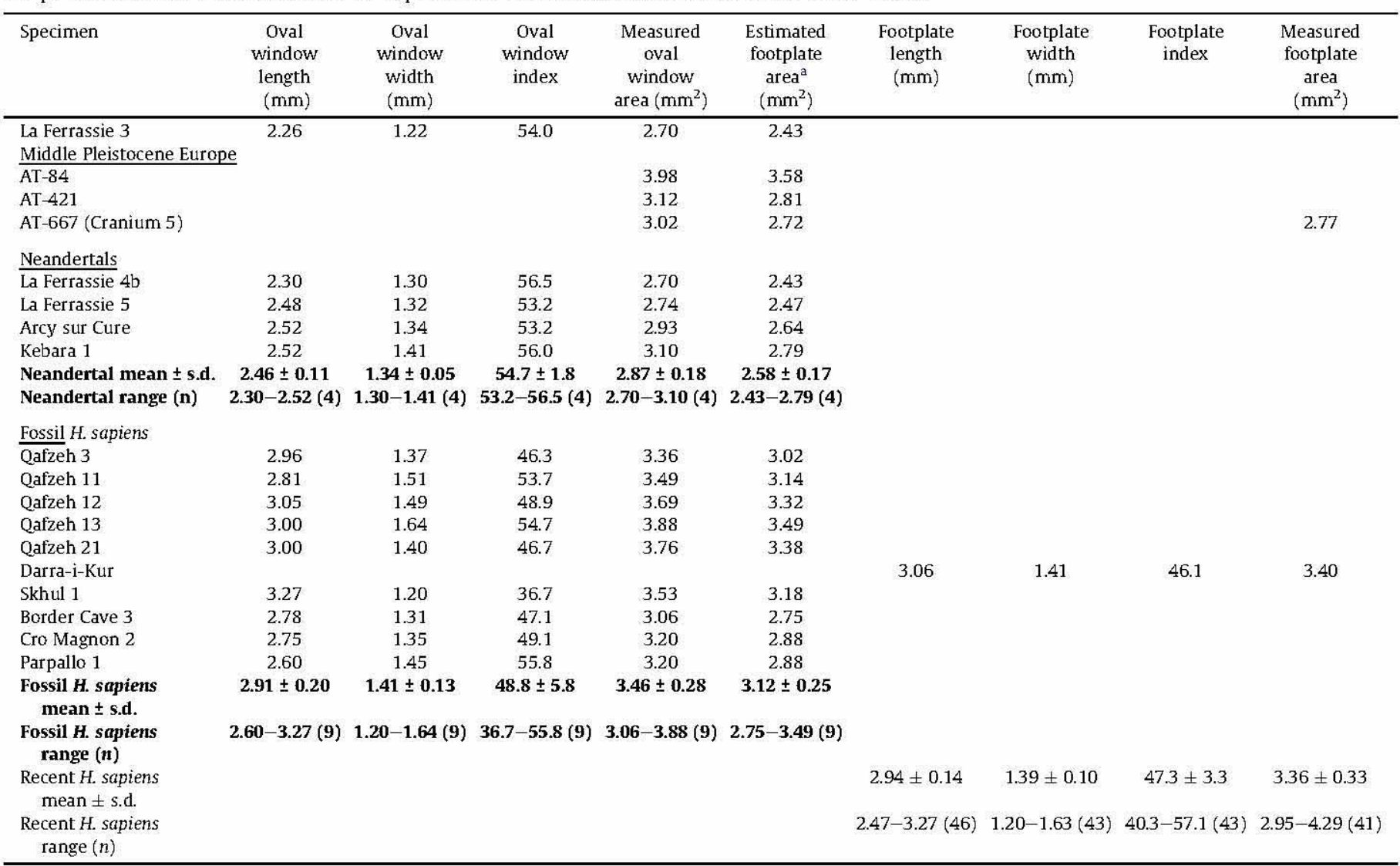

${ }^{\text {a }}$ Estimated footplate area $=($ measured oval window area $) \times 0.9$.

largely a product of variation in the width $(r=0.78)$, rather than the length, of the footplate.

Principal components analysis was carried out on the four preserved linear variables in LF3, and only the first component yielded an eigenvalue $>1.0$ (Table 9). This component explains $76.8 \%$ of the total variance (Fig. 7 ), and all of the variables showed high negative loadings. This component is clearly size-related, with higher scores being associated with smaller stapes dimensions. The two Neandertal specimens fall towards the upper end (LF3) or outside (Subalyuk 2 ) the modern human range of variation along the first component (Fig. 7), while the single fossil H. sapiens individual, Darra-i-Kur, also falls within but toward the upper end of the recent $H$. sapiens range of variation.

\section{Discussion}

Phylogenetic polarity of ear ossicle morphology

The study of the original LF3 ear ossicles has revealed a number of differences from $H$. sapiens in the ossicular chain. It is not possible to confirm based on LF3 whether Neandertals had an absolutely longer malleus and more open angle between the manubrium and corpus, as suggested by Heim (1982). Nevertheless, Neandertals can be distinguished from $H$. sapiens in showing a larger mallear head, taller incudal articular facet, depressed area on the medial surface of the incudal body, straight incudal long process, more closed angle between the incudal processes, smaller stapes with asymmetrical crura, an anteriorly skewed stapedial head and a smaller and relatively wider stapedial footplate. Similarities with $H$. sapiens include the curved lateral margin and absolute length of the malleus manubrium, the proportions of the incudal long and short processes and the malleus/ incus lever ratio. Although the polarity of many of these features is difficult to discern, a few generalizations do seem possible.

The Stw 151 stapes attributed to Australopithecus africanus shows a centrally placed stapedial head and largely symmetrical configuration of the anterior and posterior crura (Moggi-Cecchi and Collard, 2002). Thus, the Neandertal condition seems to be derived, even though this same condition can be found as an uncommon variant among recent $H$. sapiens. At the same time, the mean footplate area in Neandertals $\left(2.58 \mathrm{~mm}^{2}\right)$ is only slightly larger than that reported for $A$. africanus $\left(2.33 \mathrm{~mm}^{2}\right.$ ) (Moggi-Cecchi and Collard, 2002) despite considerable differences in body size, suggesting that this may represent a primitive retention in Neandertals.

The human-like lever ratio in LF3 appears to be a derived condition that is shared with $H$. sapiens. Most primate species have

Table 9

Results of the principal components analysis of stapes variables.

\begin{tabular}{lcc}
\hline & Factor 1 & Factor 2 \\
\hline Eigenvalue & 3.07 & 0.48 \\
\% Total variance & $76.8 \%$ & $11.9 \%$ \\
Variable factor loadings & & \\
\hline Head height & -0.801 & 0.509 \\
Total height & -0.961 & -0.205 \\
Posterior crus length & -0.858 & 0.152 \\
Anterior crus length & -0.877 & -0.389 \\
\hline
\end{tabular}




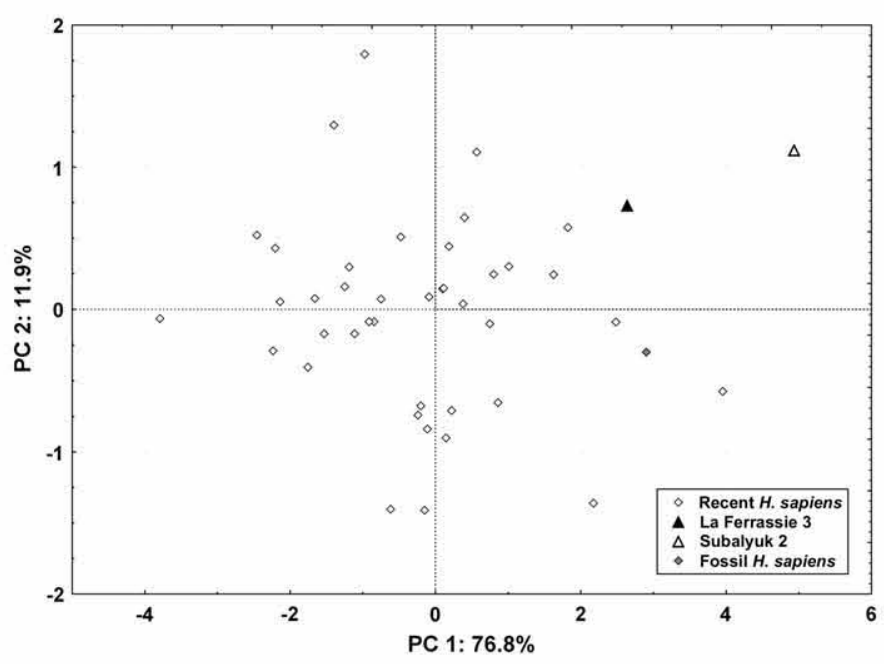

Figure 7. Scatterplot distribution of the first and second principal components based on the stapes variables. The first component largely reflects size differences, with higher values being associated with smaller stapes. The two Neandertal specimens fall toward the upper end or above the recent human range of variation along the first component, reflecting their small stapes dimensions.

higher lever ratios (Coleman and Colbert, 2010), including chimpanzees (Martínez et al., 2004). The presence of a human-like lever ratio in LF3 and the Middle Pleistocene Atapuerca (SH) individual suggests this is a shared derived condition inherited from the last common ancestor of Neandertals and $H$. sapiens.

Although many of the features mentioned above are variably present in fossil and recent $H$. sapiens, the Neandertals seem to show a nearly constant expression of these features. Thus, they consistently express a portion of the modern human range of variation and show less anatomical and metric variation than $H$. sapiens. This is true for the incus and stapes, but is less clear for the malleus since the LF3 specimen is the only Neandertal malleus published to date. Given the tight genetic control over the morphology and development of the ear ossicles (Mallo, 2001), this lower level of variation in Neandertals is consistent with a lower genetic diversity in Neandertals compared with $H$. sapiens, as suggested by ancient DNA analyses (Briggs et al., 2009).

\section{Body size and ear ossicle dimensions}

Given the extremely small dimensions of the ossicles and the differences in body mass between Neandertals and $H$. sapiens, the possible relationship of the ossicular dimensions to aspects of body size should be considered. Although body mass estimates in fossil hominins involve a number of complicating factors, the emergence of $H$. sapiens seems to have coincided with a reduction in body mass compared with their Pleistocene precursors (Ruff, 2002). The results of the present study suggest that the malleus head (and, by implication the articular facet) and incus articular facet are larger in Neandertals than $H$. sapiens. Although correlation of the incudomalleolar joint dimensions with body mass has not been investigated, joint size in the mammalian postcranial skeleton generally reflects differences in body size (Godfrey et al., 1995; Lieberman et al., 2001). Thus, the larger incudomalleolar joint in Neandertals might be taken to reflect differences in body mass.

In general, the ossicle dimensions do not appear to be related to the size of the skull in modern humans (Arensburg et al., 1981), but the lever ratio shows a weak negative correlation with skull size across primates (Coleman and Ross, 2004). Cranial dimensions do differ between Neandertals and $H$. sapiens, with the former showing, on average, longer, lower crania and somewhat larger brain sizes (Arsuaga et al., 1997). Nevertheless, the lever ratio in LF3 is close to the modern human mean, and the dimensions of the stapes, including the size of the footplate, are smaller in Neandertals. Thus, the relatively minor differences in absolute cranial size do not seem to be responsible for the differences in ossicular dimensions reported here.

More broadly, the mass of the ossicles is negatively allometric with skull mass (Nummela, 1995), and the stapes footplate area is correlated with body mass across mammals (Rosowski, 1992). The comparison of stapes footplate size between Neandertals and modern humans is revealing in this regard. Neandertals are characterized by a smaller stapes footplate area and a heavier body mass. In contrast, $H$. sapiens shows an increase in the stapes footplate area and a decrease in body mass, and seems derived in both these aspects. Interestingly, the change in stapes footplate size in $H$. sapiens is in the opposite direction of that predicted based on body mass, and represents a departure from the general mammalian pattern. The mechanism behind this increase in stapes footplate size in $H$. sapiens is currently not clear, and further study of this question is clearly warranted.

\section{Articulation of the ossicular chain}

Several aspects of the Neandertal ear ossicles suggest subtle differences from $H$. sapiens in the articulation of the ossicular chain. Although the larger incudomalleolar joint in Neandertals may reflect differences in body size, joint surface area is also correlated with the transmission of forces across the joint (Godfrey et al., 1995). Thus, the larger incudomalleolar joint surfaces in Neandertals are consistent with the capacity for transmitting larger forces through the ossicular chain.

More importantly, the more closed angle between the processes of the incus and the anteriorly skewed stapedial head clearly suggest a slightly different spatial relationship and articulation within the tympanic cavity in Neandertals compared with $H$. sapiens. Although the fossil record is limited, these are constant features in the few Neandertal fossils known. This arrangement suggests either a more posterior placement of the oval window (for the insertion of the stapes footplate) on the medial wall of the tympanic cavity or a more anterior position and/or change in the angle of the tympanic membrane (for the insertion of the malleus manubrium) at the medial end of the external auditory canal. The inner ear, like the ear ossicles themselves, is under a very tight genetic control, being fully formed and adult size at birth and is a highly conservative region evolutionarily (Jeffery and Spoor, 2004). In addition, the tight relationship between the osseous structures of the stapes footplate and oval window would seem to be more resistant to changes in their spatial arrangement within the tympanic cavity than the fibrous and elastic structure of the tympanic membrane, for insertion of the malleus manubrium.

Perhaps relevant in this regard, an embryological link between the malleus and the temporo-mandibular joint (TMJ) can be seen in the discomalleolar ligament (Rodríguez-Vázquez et al., 1993). This ligament passes anteriorly from the base of the manubrium through the glasserian fissure to insert onto the medial aspect of the cartilaginous articular capsule of the TMJ (Rodríguez-Vázquez et al., 1998). Tension applied to the discomalleolar ligament has been shown to produce movement of the malleus, suggesting a functional interdependence of the malleus and the TMJ. Neandertals have been shown to display a suite of derived features in both the TMJ and the mandibular condyle (Quam and Smith, 1998; Jabbour et al., 2002; Rak et al., 2002; Martínez et al., 2008), raising 
the possibility of a pleiotropic effect on the ossicular chain, as has been suggested previously in early hominins (Rak, 1994). Nevertheless, further study of the Neandertal tympanic cavity and middle ear ossicles are clearly necessary to confirm these hypotheses.

\section{Auditory implications}

Although the relationship between individual auditory structures and hearing performance is complex (Quam, 2006; Coleman and Colbert, 2010; Quam et al., 2012), the functional lengths of the malleus and incus and the stapes footplate area are important physiological variables in modeling audition (Rosowski, 1996; Aibara et al., 2001; Martínez et al., 2004, in press). These three variables are all strongly correlated with low frequency sensitivity (i.e. $<1 \mathrm{kHz}$ ) across primates. In addition, the incus functional length has been shown to be correlated with the presence of a notch (indicating decreased auditory sensitivity) in the audiogram around $4 \mathrm{kHz}$ across primates (Coleman and Colbert, 2010). Thus, taxa with shorter incudal functional lengths show a more pronounced notch (and hence greater decrease in auditory sensitivity) in the audiogram. Compared with chimpanzees, humans are characterized by a considerable increase in the incudal functional length (Masali and Chiarelli, 1965; Masali et al., 1991; Quam, 2006), and the absence of a notch is one of the most salient distinctions in the hearing pattern of modern humans, one that differentiates us from nearly all other primates tested to date (Coleman, 2009; Quam et al., 2012). The presence of a human-like incus functional length and lever arm ratio is consistent with a hearing pattern in Neandertals that is similar to that of living humans in showing a broadened region of heightened sensitivity in the midrange frequencies. This suggestion is further supported by the analysis of the auditory capacities in the Middle Pleistocene Atapuerca (SH) hominins, since a close phylogenetic relationship is widely recognized between these two groups of hominins (Arsuaga et al., 1997; Hublin, 2009). The Atapuerca (SH) hominins have been reconstructed to show a hearing pattern that resembles that of modern humans very closely (Martínez et al., 2004, in press; Quam et al., 2012), suggesting this is a shared derived feature inherited from the last common ancestor of Neandertals and $H$. sapiens. Given the anatomical distinctions in the Neandertal ossicular chain reported here, analysis of the auditory capacities in Neandertals should be a future research priority.

\section{Conclusion}

The present study of the LF3 ossicular chain has clarified a number of aspects regarding the anatomy and metric dimensions of the Neandertal middle ear ossicles. Several previous assertions regarding the $\mathrm{LF} 3$ ear ossicles have been revised (e.g., presence of a straight malleus manubrium, differences in the lengths of the incus processes, size of the stapes footplate). At the same time, we have also confirmed several observations made by Heim (1982) in his original study (e.g., presence of a large malleus head and incus articular facet, straight anterior margin of the incus long process, asymmetrical stapes crura and an anteriorly skewed stapes head). In addition, the present results have confirmed several suggestions made previously regarding the Neandertal ear ossicles based on more limited evidence (Quam and Rak, 2008). Far from showing no difference from $H$. sapiens (Arensburg et al., 1981, 1996), the ear ossicles have revealed subtle yet real distinctions in the ossicular chain between these two Pleistocene taxa, suggesting that the auditory ossicles are an important source of phylogenetic and paleobiological information.

\section{Acknowledgments}

We wish to thank the following institutions for access to fossil hominin and recent human specimens included in the present study: Musee de l'Homme (Paris, France), Institut de Paleontologie Humaine (Paris, France), New York Chiropractic College (Seneca Falls, USA), Cleveland Museum of Natural History (Cleveland, USA), Tel Aviv University (Tel Aviv, Israel), Instituto Português de Arqueología (Lisbon, Portugal), National Museum of Natural History-Smithsonian Institution (Washington, DC, USA), University of Witwatersrand (Johannesburg, South Africa), Ditsong National Museum of Natural History (Pretoria, South Africa) and the Museo de Prehistoria y Etnología (Valencia, Spain). We also thank T. Greiner for access to the recent human sample. This research was funded by the Leakey Foundation, the American Museum of Natural History and the Ministerio de Ciencia e Innovación of the Government of Spain, Project No. CGL2009-12703-C03-03/02.

\section{References}

Aibara, R., Welsh, J., Puria, S., Goode, R, 2001. Human middle-ear sound transfer function and cochlear input impedance. Hearing Res. 152, 100-109.

Angel, J.L., 1972. A Middle Paleolithic temporal bone from Darra-i-Kur, Afghanistan Trans. Am. Phil. Soc. 62, 54-56.

Arensburg, B., Harrell, M., Nathan, H., 1981. The human middle ear ossicles: morphometry, and taxonomic implications. J. Hum. Evol. 10, 199-205.

Arensburg, B., Nathan, H., 1971. Observations on a notch in the short (superior or posterior) process of the incus. Acta Anat. 78, 84-90.

Arensburg, B., Nathan, H., 1972. A propos de deux osselets de l'oreille moyenne d'un néandertaloïde trouvés a Qafzeh (Israel). L'Anthropologie 76, 301-308.

Arensburg, B., Pap, I., Tillier, A.M., Chech, M., 1996. The Subalyuk 2 middle ear stapes. Int J. Osteoarcheol. 6, 185-188.

Arsuaga, J.L., Martínez, I., Gracia, A., Lorenzo, C., 1997. The Sima de los Huesos crania (Sierra de Atapuerca, Spain). A comparative study. J. Hum. Evol. 33 219-282.

Blumer, W., Freedman, L., Lofgren, M., 1982. Middle ear ossicles of Australian aborigines. Archaeol. Oceania 17, 127-131.

Bouchet, A., Giraud, M., 1968. Contribution a l'etude morphologique et radiologique des osselets de l'ouie. C.R. Assoc. Anat. 53, 588-600.

Briggs, A., Good, J., Green, R., Krause, J., Maricic, T., Stenzel, U., Lalueza-Fox, C., Rudan, P., Brajković, D., Kućan, Ž., Gušić, I., Schmitz, R., Doronichev, V., Golovanova, L., de la Rasilla, M., Fortea, J., Rosas, A., Pääbo, S., 2009. Targeted retrieval and analysis of five Neandertal $m$ DNA genomes. Science $325,318-321$.

Clark, A., Glanowski, S., Nielsen, R., Thomas, P., Kejariwal, A., Todd, M., Tanenbaum, D., Civello, D., Lu, F., Murphy, B., Ferriera, S., Wang, G., Zheng, X. White, T., Sninsky, J., Adams, M., Cargill, M., 2003. Inferring nonneutral evolution from human-chimp-mouse orthologous gene trios. Science 302 1960-1963.

Coleman, M.N., 2009. What do primates hear? A meta-analysis of all known nonhuman primate behavioral audiograms. Int. J. Primatol. 30, 55-91.

Coleman, M.N., Colbert, M.W., 2010. Correlations between auditory structures and hearing sensitivity in non-human primates. J. Morphol. 271, 511-532.

Coleman, M.N., Ross, C., 2004. Primate auditory diversity and its influence on hearing performance. Anat. Rec. Part. A 281A, 1123-1137.

Crevecoeur, I., 2007. New discovery of an Upper Paleolithic auditory ossicle: the right malleus of Nazlet Khater 2. J. Hum. Evol. 52, 341-345.

Frenz, D., McPhee, J., van de Water, T., 2001. Structural and functional development of the ear. In: Jahn, A., Santos-Sacchi, J. (Eds.), Physiology of the Ear. Singular, San Diego, pp. 191-214 (second ed.).

Godfrey, L, Sutherland, M., Paine, R. Williams, F, Boy, D., VuillaumeRandriamanantena, M., 1995. Limb joint surface areas and their ratios in Malagasy lemurs and other mammals. Am. J. Phys. Anthropol. 97, 11-36.

Heim, J.L., 1982. Les Enfants Neandertaliens de La Ferrassie. Masson, Paris.

Heron, I., 1923. Measurements and observations upon the human auditory ossicles. Am. J. Phys. Anthropol. 6, 11-26.

Hublin, J., 2009. The origin of Neandertals. Proc. Natl. Acad. Sci. 106, 16022-16027.

Jabbour, R., Richards, G., Anderson, J., 2002. Mandibular condyle traits in Neanderthals and other Homo: a comparative, correlative, and ontogenetic study Am. J. Phys. Anthropol. 119, 144-155.

Jeffery, N., Spoor, F., 2004. Prenatal growth and development of the modern human bony labyrinth. J. Anat. 204, 71-92.

Kachigan, S., 1991. Multivariate Statistical Analysis. A Conceptual Introduction, second ed. Radius Press, New York.

Kirikae, I., 1960. The Structure and Function of the Middle Ear. University of Tokyo Press, Tokyo.

Lieberman, D., 1995. Testing hypotheses about recent human evolution from skulls: integrating morphology, function, development and phylogeny. Curr. Anthropol. 36, 159-197. 
Lieberman, D., Devlin, M., Pearson, O., 2001. Articular area responses to mechanical loading: effects of exercise, age, and skeletal location. Am. J. Phys. Anthropol. $116,266-277$

Lisonek, P., Trinkaus, E., 2006. The auditory ossicles. In: Trinkaus, E., Svoboda, J. (Eds.), Early Modern Human Evolution in Central Europe. The People of Dolni Vestonice and Pavlov. Oxford University Press, Oxford, pp. 153-155.

Mallo, M., 1998. Embryological and genetic aspects of middle ear development. Int. J. Dev. Biol. 42, 11-22.

Mallo, M., 2001. Formation of the middle ear: recent progress on the developmental and molecular mechanisms. Dev. Biol. 231, 410-419.

Martínez, I., Quam, R, Arsuaga, J., 2008. Evolutionary trends in the temporal bone in the Neandertal lineage: a comparative study between the Sima de los Huesos (Sierra de Atapuerca) and Krapina samples. In: Monge, J. (Ed.). New Insights on the Krapina Neandertals: 100 Years after Gorjanović-kramberger. Croatian Natural History Museum, Zagreb, pp. 75-80.

Martínez, I., Rosa, M. Arsuaga, J, Jarabo, P, Ouam, R, Lorenzo, C, Gracia, A Carretero, J., Bermûdez de Castro, J., Carbonell, E., 2004. Auditory capacities in Middle Pleistocene humans from the Sierra de Atapuerca in Spain. Proc. Natl. Acad. Sci. 101, 9976-9981.

Martínez, I., Rosa, M., Quam, R., Jarabo, P., Lorenzo, C., Bonmatí, A., Gómez-Olivencia, A., Gracia, A., Arsuaga, J. Communicative capacities in Middle Pleistocene humans from the Sierra de Atapuerca in Spain. Quatern. Int., in press.

Masali, M., 1964. Dati sulla variabilitá morfometrica e ponderale degli ossicini delludito nelíuomo. Arch. Ital. Anat. Embriol. 69, 435-446.

Masali, M., Chiarelli, B., 1965. Analisi morfometrica comparata degli ossicini dell'udito dei Primati II. L'incudine nelle scimmie del Vecchio Mondo e nell'uomo. Riv. Antropol. 52, 147-157.

Masali, M., Maffei, M., Borgognini Tarli, S.M., 1991. Application of a morphometric model for the reconstruction of some functional characteristics of the external and middle ear in Circeo 1. In: Piperno, M., Scichilone, G. (Eds.), The Circeo 1 Neandertal Skull: Studies and Documentation. Instituto Poligrafico e Zecca Dello Stato, Rome, pp. 321-338.

Maureille, B., 2002. A lost Neanderthal neonate found. Nature 419, 33-34.

Moggi-Cecchi, J., Collard, M., 2002. A fossil stapes from Sterkfontein, South Africa, and the hearing capabilities of early hominids. J. Hum. Evol. 42, 259-265.

Mutaw, R., 1986. Human Auditory Ossicle Variation and Function. Department of Anthropology, University of Colorado, Boulder.

Nummela, S., 1995. Scaling of the mammalian middle ear. Hearing Res. 85, 18-30.

Pap, I., Tillier, A., Arensburg, B., Chech, M., 1996. The Subalyuk Neanderthal remains (Hungary): a re-examination. Annls. Hist.-nat. Mus. Nat Hung. 88, 233-270.

Ponce de León, M., Zollikofer, C., 1999. New evidence from Le Moustier 1: computerassisted reconstruction and morphometry of the skull. Anat Rec. 254, 474-489.

Quam, R, 2006. Temporal Bone Anatomy and the Evolution of Acous tic Capacities in Fossil Humans. Department of Anthropology, State University of New York Binghamton.

Quam, R., Martinez, I., Arsuaga, J.L., 2006. Middle Pleistocene auditory ossicles from the Sierra de Atapuerca (Spain). Am. J. Phys. Anthropol. 42 (Suppl.), 149.
Quam, R., Martínez, I., Lorenzo, C., Bonmatí, A., Rosa, M., Jarabo, P., Arsuaga, J., 2012 Studying Audition in Fossil Hominins: a New Approach to the Evolution of Language? In: Jackson, M. (Ed.), Psychology of Language. Nova Science Publishers, Inc., Hauppauge, NY, pp. 47-95.

Quam, R, Rak, Y., 2008. Auditory ossicles from southwest Asian Mousterian sites. J. Hum. Evol. 54, 414-433.

Quam, R., Smith, F.H., 1998. Reassessment of the Tabun C2 mandible. In: Akazawa, T. (Ed.), Neandertals and Modern Humans in Western Asia. Plenum Press, New York, pp. 405-421.

Rak, Y., 1994. The middle ear of Australopithecus robustus. Does it bear evidence of a specialized masticatory system? In: Corruccini, R, Ciochon, R. (Eds.), Integrative Paths to the Past: Paleoanthropological Advances in Honor of F. Clark Howell. Prentice Hall, Englewood Cliffs, pp. 223-227.

Rak, Y., Ginzburg, A., Geffen, E., 2002. Does Homo neanderthalensis play a role in modern human ancestry? The mandibular evidence. Am. J. Phys. Anthropol. 119 199-204.

Rodríguez-Vâzquez, J., Mérida-Velasco, J., Jiménez-Collado, J., 1993. Relationships between the temporomandibular joint and the middle ear in human fetuses. J. Dent Res. 72, 62-66.

Rodríguez-Vâzquez, J., Mérida-Velasco, J., Mérida-Velasco, J., Jiménez-Collado, J., 1998. Anatomical considerations on the discomalleolar ligament. J. Anat 192 $617-621$.

Rosowski, J., 1992. Hearing in transitional mammals: predictions from the middle ear anatomy and hearing capabilities of extant mammals. In: Webster, D. (Ed.), The Evolutionary Biology of Hearing. Springer-Verlag, New York pp. $615-632$

Rosowski, J., 1996. Models of external- and middle-ear function. In: Hawkins, $\mathrm{H}$ (Ed.), Auditory Computation. Springer, New York, pp. 15-61.

Ruff, C., 2002. Variation in human body size and shape. A. Rev. Anthropol. 31 211-232.

Scheuer, L., Black, S., 2000. Developmental Juvenile Osteology. Academic Press, San Diego.

Siori, M., Monchietto, M., Masali, M., 1995. Morphometrics of human auditory ossicles from Antinoe Necropolis (Egypt). Int J. Anthropol. 10, 29-36.

Spoor, F., 2002. The auditory ossicles. In: Zilhão, J., Trinkaus, E. (Eds.), Portrait of the Artist as a Child. The Gravettian Human Skeleton from the Abrigo Do Lagar Velho and Its Archeological Context. Instituto Português de Arqueologia, Lisbon, pp. 293-296.

Spoor, F., Hublin, J., Braun, M., Zonneveld, F., 2003. The bony labyrinth of Neanderthals. J. Hum. Evol. 44, 141-165.

Tillier, A.M., 1999. Les Enfants Mousteriens de Qafzeh: Interpretation Phylogenetique et Paleoauxologique. CNRS Editions, Paris.

Wever, E., Lawrence, M., 1954. Physiological Acoustics. Princeton University Press, Princeton.

Xu, P.-X., Adams, J., Peters, H., Brown, M., Heaney, S., Maas, R, 1999. Eya1-deficient mice lack ears and kidneys and show abnormal apoptosis of organ primordia. Nat Gen. 23, 113-117. 